\title{
Design e tecnologia sexual:
}

\section{breve panorama a partir de Foucault e Preciado}

ISSN: 2358-0844

n. $16, v .3$

out.2021-dez.2021

p. $63-81$
(Design and sexual technology:

a brief panorama based on Foucault and Preciado)

(Diseño y tecnología sexual: un breve panorama desde Foucault y Preciado)

\section{Marcos N. Beccari ${ }^{1}$}

RESUMO: Este ensaio delineia um breve panorama conceitual em torno da noção de "tecnologia sexual" nos pensamentos de Paul B. Preciado e Michel Foucault, com o intuito de depreender tal dimensão tecnológica enquanto uma prática de design. Para tanto, apresento a perspectiva de Foucault acerca da sexualidade, destacando a filiação de Preciado a essa abordagem e como o design pode ser entendido sob esse prisma. Esclareço, na sequência, a noção de "tecnologia" (cara a Foucault) e o sentido de dizer que o sexo é tecnológico, com especial atenção ao conceito de "dildo" (caro a Preciado). Contextualizo, então, algumas das tecnologias sexuais historicamente recentes ao longo de um panorama abreviado da invenção do (hetero)sexo, na esteira da genealogia do orgasmo feminino traçada por Preciado. Uma vez assinalado que a heterossexualidade talvez seja o design mais bem-sucedido da história, concluo apontando que, no terreno da tecnologia sexual, o design aciona uma via de mão dupla: pela manutenção e reforço da heteronormatividade, possibilita, paradoxalmente, a subversão da sexualidade assim construída. Por fim, forneço ainda um "breve glossário contrassexual” para esclarecer alguns termos-chave abordados neste artigo.

PALAVRAS-CHAVE: Paul B. Preciado. Design. Tecnologia. Sexualidade.

\begin{abstract}
This essay outlines a brief conceptual panorama around the notion of "sexual technology" as thought by Paul B. Preciado and Michel Foucault, to understand this technological dimension as a design practice. For this, I present Foucault's perspective on sexuality, highlighting Preciado's affiliation with this approach and how design can be understood in this light. Next, I clarify the notion of "technology" (dear to Foucault) and the sense of saying that sex is technological, with special attention to the concept of "dildo" (dear to Preciado). Then I contextualize some of the historically recent sexual technologies along an abridged panorama of the invention of (hetero)sex, analogously to the genealogy of the female orgasm traced by Preciado. Once pointed out that heterosexuality is perhaps the most successful design in history, I conclude by stating that, in the field of sexual technology, design operates in an ambivalent way: by maintaining and reinforcing heteronormativity, it paradoxically enables the subversion of the sexuality thus designed. Finally, I also provide a "brief counter-sexual glossary" to clarify some key terms covered in this article.

Keywords: Paul B. Preciado. Design. Technology. Sexuality.

Resumen: Este ensayo esboza un breve panorama conceptual sobre la noción de "tecnología sexual” en el pensamiento de Paul B. Preciado y de Michel Foucault, con el propósito de entender esta dimensión tecnológica como práctica de diseño. En primer lugar, presento la perspectiva de Foucault sobre la sexualidad destacando la afiliación de Preciado en este enfoque y cómo se puede concebir el diseño desde esta perspectiva. A continuación, aclaro la noción de "tecnología" (central para Foucault) y el sentido de decir que el sexo es tecnológico, con especial atención al concepto de "dildo" (central para Preciado). Luego, contextualizo algunas de las tecnologías sexuales históricamente recientes a lo largo de un panorama abreviado de la invención del (hetero)sexo, análogamente a la genealogía del orgasmo
\end{abstract}

1 Universidade Federal do Paraná. E-mail: marcosbeccari@ufpr.br. 
femenino trazada por Preciado. Una vez señalado que la heterosexualidad es quizás el diseño más exitoso de la historia, concluyo afirmando que, en el campo de la tecnología sexual, el diseño opera de manera ambivalente: al mantener y reforzar la heteronormatividad paradójicamente permite la subversión de la sexualidad así construida. Finalmente, esbozo un breve glosario contrasexual, con el fin de aclarar algunos términos clave utilizados en este artículo.

Palabras clave: Paul B. Preciado. Diseño. Tecnología. Sexualidad.

A metafísica da falta, que certas teologias e certas formas de psicanálise compartilham, gostaria de nos convencer de que falta alguma coisa a todos nós. Dizem-nos que o mundo está em ordem porque às mulheres falta o pênis, porque aos homens falta os úteros/seios, porque aos homens e às mulheres falta o 'falo transcendental' — ou o megadildo. Dizem-nos que aos animais falta a alma, e que às máquinas cibernéticas falta a carne e a vontade que as conexões elétricas vêm compensar com um excesso de informação... Não nos falta nada. [...] Não nos falta nem o pênis nem os seios. O corpo já é um território pelo qual órgãos múltiplos e identidades diversas cruzam.

(Manifesto contrassexual: práticas subversivas de identidade sexual, Paul B. Preciado)

\section{Introdução}

Em nenhum dos quatro volumes da História da sexualidade ${ }^{2}$ Foucault aborda a sexualidade como uma questão isolada e autônoma, e sim como resultante de tudo o que historicamente a instituiu ao seu redor, a começar pela conjuntura do século XIX, marcada por histerização do corpo feminino, pedagogização do sexo da criança, socialização reguladora das condutas de procriação e psquiatrização do prazer perverso/desviante. No primeiro volume da História da sexualidade, tais questões são abordadas à luz do processo maior que remonta à transformação da sociedade europeia do final do século XVIII, que saiu de um regime de poder soberano em direção a um regime de poder disciplinador até culminar no regime do biopoder — isto é, aquele que planeja e regula a vida no nível da população. Ultrapassando a esfera jurídica e o domínio punitivo, essa nova forma de poder torna-se uma tecnologia política, por meio da arquitetura, estatística, demografia, projetos de saúde pública etc., até moldar o próprio corpo do indivíduo moderno. Já nos volumes posteriores da História da sexualidade, vemos, em resumo, um longo recuo histórico à Antiguidade grega e judaico-cristã a partir de um novo interesse de investigação: o entrelaçamento das práticas de subjetivação com as técnicas de conduta/governo (como o cuidado de si e o poder pastoral).

Teresa de Lauretis (1994a, p. 208) reconhece que tais obras, embora sejam centradas na noção de sexualidade, contribuíram para o entendimento do gênero não como uma propriedade $a$ priori dos corpos, mas como um "conjunto de efeitos produzidos em corpos, comportamentos e relações sociais por meio do desdobramento de uma complexa tecnologia política”. No entanto, a autora feminista adverte que o olhar de Foucault é “androcêntrico” por não considerar as

2 O quarto volume, intitulado Confissões da carne, foi publicado em 2018 pela editora Gallimard. 
assimetrias de gênero, omissão esta que relegaria sua abordagem a um rol de teorias que "negam o gênero”. (LAURETIS, 1994a, p. 223) Aqui é necessário indagar: o fato de Foucault nunca ter falado em termos de "gênero" significa que ele de fato o negava? Lauretis parece se referir especificamente à negação da influência das relações sociais de gênero em um processo histórico de opressão sexual das mulheres. E o que Foucault de fato questiona é tal processo, não o gênero — que, sob o prisma foucaultiano, seria um dos elementos da produção (e não opressão) da sexualidade, ensejando o que Preciado chama de contrassexualidade:

O nome contrassexualidade provém indiretamente de Michel Foucault, para quem a forma mais eficaz de resistência à produção disciplinar da sexualidade em nossas sociedades liberais não é a luta contra a proibição (como aquela proposta pelos movimentos de liberação sexual antirrepressivos dos anos setenta), e si a contraprodutividade, isto é, a produção de formas de prazer-saber alternativas à sexualidade moderna (PRECIADO, 2017, p. 22).

Se no primeiro volume da História da sexualidade Foucault (2005) critica os discursos pautados na ideia de "opressão", é porque seus estudos apontam que, historicamente, o sexo (enquanto prática, categoria biológica, critério de identidade/diferença etc.) revela-se mais produzido do que reprimido, de modo que o sistema de produção, aliado às assimetrias de gênero, "autoriza a sujeição das mulheres como força de trabalho sexual e como meio de reprodução”. (PRECIADO, 2017, p. 26) Foucault mostrou, por exemplo, como a histerização da mulher no século XIX decorria da ideia do sexo como, de um lado, propriedade do homem e, de outro, função do corpo da mulher. Significa que "é o dispositivo de sexualidade que, em suas diferentes estratégias, instaura essa ideia 'do sexo’ [...] É pelo sexo efetivamente [...] que todos devem passar para ter acesso à sua própria inteligibilidade”. (FOUCAULT, 2005, p. 145-146) Conforme sumariza Gayle Rubin,

Foucault critica a visão tradicional da sexualidade como impulso natural da libido para se liberar da coerção social. Ele argumenta que os desejos não são entidades biológicas preexistentes, mas, em vez disso, são constituídos no decorrer de práticas sociais específicas ao longo da história. Foucault enfatiza mais os aspectos de organização social do sexo que seus elementos repressivos, ressaltando que novas sexualidades são constantemente produzidas. (RUBIN, 2017, p. 78) ${ }^{3}$

O panorama abreviado acima serve aqui para delimitar uma perspectiva teórica: o "sexo” não existe apartado de uma verdade e uma visualidade do sexo; por sua vez, "sexualidade" designa um conjunto de discursos e tecnologias de normalização sexual que, para Foucault, constitui o cerne da produção e do governo das subjetividades. O próprio prazer sexual só

3 Adiante, Rubin acrescenta que "Foucault deixa bastante claro que não está negando a existência da repressão sexual, mas sim a inscrevendo dentro de uma dinâmica mais ampla". (RUBIN, 2017, p. 80) 
emerge, desse ponto de vista, enquanto efeito "tecnossomático" de uma dada sexualidade ${ }^{4}$. Na prática, as categorias de gênero, sexo biológico, identidade etc. são ressituadas como mecanismos, estratégias e usos em um sistema tecnológico mais amplo, aquele dos processos políticos, econômicos, médicos e jurídicos de naturalização do sexo. Em 1868, por exemplo, os termos "heterossexual” e "homossexual” foram pela primeira vez adotados enquanto categorias, precisamente quando Richard Von Krafft-Ebing (1998) criou uma enciclopédia das sexualidades normais e desviantes. Essa verdade sexual, uma vez codificada visualmente ao modo de uma taxonomia anatômica, sustentaria as leis de criminalização da sodomia que se espalharam pela Europa no final do século XIX. Quanto à oposição biológica homem-mulher, hoje sua atribuição “poderia ser resumida a uma equação banal: ter ou não ter um pênis de um centímetro e meio no momento do nascimento”. (PRECIADO, 2018, p. 77)

Parece claro, pois, o quanto a dimensão discursiva simultaneamente orienta e instaura o que entendemos por “sexo”. Mas no presente artigo, inspirado em Paul B. Preciado - que, além de ser foucaultiano, produziu uma filosofia diretamente ligada à vivência de uma sexualidade desviante (como, aliás, também foi o caso de Foucault) -, pretendo abordar a dimensão tecnológica (mais do que a discursiva) da sexualidade, uma vez que é nessa dimensão que o design parece exercer sua função mais poderosa: a de materializar discursos e valores. Quanto a isso, não é difícil perceber, conforme já assinalei noutro momento (BECCARI, 2018), o quanto o design logra em consolidar e potencializar toda sorte de estereótipo normativo, como nos notórios exemplos da sinalização de banheiros “masculino” e “feminino” e da história da moda. Ao mesmo tempo, porém, esse mesmo processo pode engendrar, como em um curto-circuito, possibilidades inesperadas de subversão dos mesmos valores que ele materializa, deslocando-os, reinterpretando-os e reinscrevendo-os - a exemplo do vibrador, projetado inicialmente com fins médico-terapêuticos para "crises de histeria"6.

Dito de outro modo, o design é, por um lado, um dos elementos necessários à produção e à manutenção da normatividade sexo/gênero ${ }^{7}$, mas também é o que possibilita, por outro, práticas contrassexuais, isto é, formas subversivas de sexualidade. Isso ao menos se

4 Nos termos de Preciado (2017, p. 207), “o prazer não vem do corpo, seja masculino ou feminino, e sim da encarnação prostética, da interface, ali onde o natural e o artificial se tocam".

5 Estou ciente de que, em termos biológicos, trata-se estritamente de cromossomos XY ou XX, mas o fato é que a análise cromossômica quase nunca é empregada para a identificação do sexo de um bebê. Ademais, no caso dos bebês "intersexuais" (outrora qualificados como "hermafroditas"), a configuração genética não implica necessariamente qualquer traço anatômico distintivo. Ver, a esse respeito, Preciado (2017, p. 130-144).

6 Para uma história visual da histeria, ver: Didi-Huberman (2015). Para uma história das tecnologias do corpo histérico, ver: Maines (2001).

7 A expressão "sistema sexo/gênero" foi cunhada em 1975 por Gayle Rubin para assinalar a vinculação estrutural entre sexo e gênero por meio de dicotomias como homem-mulher, masculino-feminino e hetero-homo. Ver, a esse respeito, Rubin (2017, p. 9-61). 
considerarmos, como Preciado, que “a falha é constitutiva da máquina heterossexual”. (PRECIADO, 2017, p. 29-30) Aqui, “design” não se refere ao campo disciplinar ou à prática efetiva dos designers, mas ao amplo processo de materialização de discursos e valores por meio de produtos, imagens, corpos e modos de ser. Devo também pontuar, ademais, que a obra de Preciado parece estar diretamente envolvida com tal acepção de design, devido ao interesse do filósofo pela arquitetura, a sua atuação como curador de arte e à depuração da tecnologia fármaco-sexual a partir da transformação de seu próprio corpo ${ }^{8}$.

\section{0 sexo como tecnologia}

[...] a expressão techné (forma abstrata do verbo tikto, que significa 'engendrar', 'gerar') remete ao mesmo tempo, em grego, a formas de produção artificial e de geração natural. A palavra grega para designar os geradores não é outra que teknotes, e para designar o germe, tekton. Como exemplo paradigmático de contradição cultural, a tecnologia recorre simultaneamente à produção artificial (onde techné = poiesis) e à reprodução sexual ou 'natural' (onde techné = geração). (PRECIADO, 2017, p. 150)

É preciso esclarecer, antes de tudo, a noção de “tecnologia” e o sentido de dizer que o sexo é tecnológico. Note-se, a princípio, como a maioria das técnicas associadas ao sexo tem como alvo o corpo das mulheres: os métodos contraceptivos, os medicamentos e tratamentos, a inseminação artificial, os procedimentos de aborto etc. ${ }^{9}$ Não surpreende que as feministas tenham sido as primeiras a inquirir essa subordinação tecnológica das mulheres. Sob esse prisma (que era pacífico até a publicação, em 1985, do Manifesto ciborgue de Donna Haraway), o dildo figura como instrumento emblemático do poder patriarcal: enquanto utensílio sexual que remete à forma-função fálica, o dildo foi interpretado amiúde como sintoma falocêntrico, como um “substituto” do pênis. Contudo, uma visita rápida a qualquer sex shop é suficiente para notar que os dildos não têm necessariamente um formato fálico. Nesse sentido, de acordo com Preciado,

A teoria lésbica separatista, que critica a utilização do dildo por sua cumplicidade com os signos de dominação masculina, ainda acredita na realidade do pênis como sexo. Nesse viés erótico hiperfeminilizante, a ausência que estrutura o corpo, fiel a um esquema corporal monocêntrico e totalizador, está de luto pelos resquícios do mesmo sistema falocêntrico que critica. (PRECIADO, 2017, p. 151)

8 Paul B. Preciado nasceu em 1970, na Espanha, sob o corpo e o nome de Beatriz Preciado. Após obter um mestrado em Filosofia pela New School for Social Research, além de ter participado, a convite de Derrida, dos seminários da École des Hautes Études de Paris, Preciado doutorou-se em Teoria da Arquitetura pela Universidade de Princeton sob a orientação de Beatriz Colomina. Hoje, ele atua como curador e pesquisador do Museu de Arte Contemporânea de Barcelona e leciona em universidades de Paris, Barcelona e Nova York. Sua obra teórica debruça-se sobre o tema geral da tecnopolítica do sexo a partir de uma escrita autobiográfica — ou melhor, como o filósofo esclarece no início de Testo Junkie: "Este livro não é uma autobiografia, mas um protocolo de intoxicação voluntária à base de testosterona”. (PRECIADO, 2018, p. 13)

9 O fato de ainda não existir, por exemplo, uma versão do Viagra para mulheres corrobora esse ponto. 
Na contramão dessa perspectiva, o filósofo elege o dildo como noção central de seu Manifesto contrassexual, abrindo-o com o seguinte axioma: “um dildo não é um 'pinto de plástico', e sim, em que pesem as aparências, um pinto é um dildo de carne”. (PRECIADO, 2017, p. 19, nota 2) Ao estabelecer que o dildo antecede o pênis e atribuir-lhe uma origem e um arquétipo ontológicos, Preciado enfatiza a função paradoxal de um suplemento que produz aquilo que supostamente vem para suplantar. Depreende-se isso, em primeiro lugar, da seguinte constatação de Lauretis (1994b, p. 101): se no imaginário heterossexual a "boneca inflável” é o correlato do dildo, é menos por ela imitar o corpo feminino do que por modelá-lo aos costumes masculinos. Resta evidente, ademais, a assimetria de um mercado em que homens podem comprar uma cópia da totalidade do corpo feminino, enquanto as mulheres devem se contentar com uma (suposta) réplica do pênis. Nessa constatação, contudo, o dildo mostra-se mais como um significante crítico, ainda não propositivo. Então Preciado nos indaga: e se o dildo não for apenas a réplica de um único membro? De fato, se suspendermos a distinção entre o orgânico (carne) e o inorgânico (plástico), o dildo se revela como uma tecnologia sexual tanto quanto as mãos, a língua, o chicote, as algemas, a ‘cinta caralha’, os lubrificantes e o próprio pênis.

A questão é que "se o pênis é para a sexualidade o que Deus é para a natureza, o dildo torna efetiva, no domínio da relação sexual, a morte de Deus anunciada por Nietzsche. [...] Torna-se necessário filosofar não a golpes de martelo, e sim de dildo”. (PRECIADO, 2017, p. 80) Mais do que uma crítica ao patriarcado, trata-se aqui de uma proposição que dinamita a heteronormatividade a partir de seu interior, explicitando a arbitrariedade e a artificialidade de um membro privilegiado que se faz passar por matéria-prima do sexo. Pois se o dildo não funciona do modo que se espera, como mero ‘consolo' ou substituto peniano, é porque seu uso ocorre à maneira imprevisível de um prazer plástico: "Não há orifício que lhe esteja naturalmente reservado. A vagina não lhe é mais apropriada que o ânus”. (PRECIADO, 2017, p. 83) Longe de encerrar, com efeito, a identidade sexual ou de gênero de quem o usa, o dildo é um objeto móvel que, pela reversibilidade de seu uso, dissolve a estabilidade binária das posições passiva e ativa - e, de forma mais concreta e irreversível, ameaça a premissa do corpo orgânico enquanto meio próprio da sexualidade.

Em outras palavras, o dildo nos permite compreender o sexo enquanto tecnologia - noção que Foucault passa a valorizar no final dos anos 1970, após ter detalhado a noção de micropoder como fluxo produtivo que circula nos diversos níveis da sociedade, do nível abstrato do Estado ao da corporalidade. A tecnologia é então definida como um complexo de poder-saber que conjuga discursos e dispositivos, corpos e instrumentos, códigos e gestos para a regulação dos regimes de verdade. Tal concepção passa ao largo da compreensão redutora da tecnologia 
enquanto domínio das máquinas e do progresso científico, assim como excede o conjunto de técnicas aplicadas ao corpo feminino para fins de opressão patriarcal. Mesmo porque Foucault já havia mostrado que o controle mais eficaz da sexualidade não ocorre na forma de repressão, e sim pela produção de diferentes desejos e prazeres que supostamente emanam de predisposições naturais e que são assimilados como “identidades sexuais”. Ademais, é cada vez mais difícil localizar onde terminam os “corpos naturais” e onde começam as "tecnologias artificiais”, sobretudo quando se trata de implantes, marca-passos, hormônios, transplantes de órgãos, a gestão médico-química do sistema imunológico afetado pelo HIV etc.

Em última análise, nunca foi simples isolar os corpos da tecnologia que os fazem “funcionar”. O próprio termo “órgão”, afinal, deriva do grego ergon, que designa uma parte necessária ao funcionamento de determinado processo ou atividade. Nesse sentido, em que medida um martelo, que prolonga a mão, ou um telescópio, que estende o alcance do olho, não seriam órgãos? Como argumenta Preciado, os órgãos humanos têm sido há muito tempo visualizados como próteses, tanto quanto as máquinas foram concebidas como organismos. Especialmente ao longo do século XX, as próteses tornam-se cruciais não apenas na cadeia de produção industrial (possibilitando a reintegração dos corpos mutilados nas guerras), como também para explicitar o caráter prostético de um corpo que, por poder ser reconstruído, também pode ser desconstruído, deslocado, incrementado - ao mesmo tempo em que a prótese excedia o perímetro corporal:

Como prótese do ouvido, o telefone permite a dois interlocutores distantes estabelecer comunicação. A televisão é uma prótese do olho e do ouvido que permite a um número indefinido de espectadores compartilharem uma experiência ao mesmo tempo comunitária e desencarnada. O cinema poderia ser pensado retroativamente como uma prótese do sonho. [...] A arquitetura, os automóveis e outros meios de transporte são também próteses complexas com as quais outras próteses-da-sensibilidade, com seus sistemas e redes de comunicação, do telefone ao computador, podem ser conectadas. (PRECIADO, 2017, p. 164-165)

Com efeito, toda prótese enseja uma nova atividade que requer, por sua vez, ser tecnologicamente suprida. A máquina de escrever é elucidativa quanto a isso: inventada originalmente para que pessoas cegas pudessem se servir de uma escrita mecânica, logo instauraria a prática de escrever "sem olhar as teclas", conforme ensinavam os cursos de datilografia. Ou seja, projetada num primeiro momento para remediar uma falta, a prótese termina por criar um novo modo de agir (e de ser), ao ponto de nos sentirmos "incompletos" quando nos desconectamos dela. Retomando o domínio sexual, um caso quase análogo ao da máquina de escrever reside na tecnologia da reprodução in vitro: inicialmente desenvolvida para compensar uma “deficiência” da chamada “procriação natural”, essa tecnologia revelou que o 
coito heterossexual não é o único meio possível de reprodução. Diante, pois, desse potencial das próteses em transformar nossas práticas e a própria compreensão do que somos, Preciado propõe que “o sexo e o gênero deveriam ser considerados como formas de incorporação prostética”. (PRECIADO, 2017, p. 166) $)^{10}$

Essa proposta é consoante à de Donna Haraway (2009) em seu Manifesto ciborgue, cuja metáfora central remete a um sistema aberto de próteses elétricas e orgânicas. O ciborgue não é um robô ou um computador, mas um organismo vivo, maleável e passível de reconstruções; por conseguinte, a "política ciborgue” contesta as tradicionais concepções de corpos e modos de vida por meio da explicitação dos inúmeros arranjos possíveis de subjetividade e de organismos. Dessa abordagem, o que mais interessa a Preciado é a contundência de Haraway em se desviar do identitarismo, voltando-se aos modos pelos quais o corpo ao mesmo tempo é construído e se (re)constrói como “identidade”.

Remetendo-se também a Rubin (2017), em sua ênfase à materialidade da produção corposexual, Preciado empreende uma história queer da sexualidade ${ }^{11}$, no sentido de "reconstituir o lugar que o dildo ocupa na complexa trama de tecnologias de produção, de poder e, finalmente, de tecnologias do eu”, além de insistir que "nenhum instrumento de dominação está a salvo de ser pervertido e reapropriado no interior do que chamarei, seguindo as intuições de Foucault, de distintas 'práticas de resistência””. (PRECIADO, 2017, p. 98) É por esse caminho que Preciado traçou, ainda enquanto se chamava Beatriz, uma "breve genealogia do orgasmo feminino" a partir de duas tecnologias aparentemente opostas que, do final do século XVIII até meados do século XX, se desenvolveram lado a lado: a da repressão da masturbação e a da cura da histeria. Parece-me pertinente, pois, contextualizar tal genealogia num panorama mais amplo, embora aqui abreviado: aquele da invenção do próprio (hetero)sexo.

\section{A invenção do (hetero)sexo}

As teorias aristotélicas da procriação humana falam do esperma como um líquido que contém 'homens in nuce', 'homúnculos' que devem ser depositados no ventre passivo da mulher. Essa teoria, que não foi refutada até a descoberta dos ovários no século XVII, entendia a procriação como uma tecnologia agrícola dos corpos, na qual os homens são os técnicos e as mulheres campos naturais de cultivo. (PRECIADO, 2017, p. 150)

10 Tal asserção implica, diga-se de passagem, uma crítica severa: “Estou sugerindo que, talvez, se as hipóteses do chamado 'construtivismo de gênero' foram aceitas sem produzir transformações políticas significativas, pode ser exatamente porque tal construtivismo não só mantém como depende de uma distinção entre sexo e gênero que torne efetiva a oposição tradicional entre cultura e natureza e, por extensão, entre tecnologia e natureza. A necessidade de lutar contra as formas normativas de essencialismo de gênero de toda espécie teria feito o feminismo e o pós-feminismo dos anos noventa vítimas de suas próprias depurações discursivas”. (PRECIADO, 2017, p. 94)

11 Isto é, uma história a partir de um ponto de vista queer, o que é diferente de uma história da sexualidade queer (enquanto temática). 
Em Making Sex, o historiador Thomas Laqueur (1992, p. 63-108) descreve como, no século XVII, a anatomia sexual ainda era concebida em termos de um "sistema de similaridades" com base no corpo masculino: os ovários eram considerados os testículos internos e a vagina, o receptáculo perfeito para acolher o pênis. Trata-se, portanto, de um modelo “monossexual” que faz do corpo feminino mero arranjo reprodutivo, de sorte que mulheres incapazes de engravidar ou de amamentar e cuidar de uma criança eram consideradas “menos” mulheres que as demais. É desse modo que o sexo e a sexualidade (termo que, contudo, não existe antes de 1880) tornam-se tecnologias somatopolíticas, isto é, que se materializam e funcionam no corpo humano. A partir de então, o trabalho e a sexualidade conjugarão progressivamente um mesmo circuito "ergoeconômico”.

No começo do século XVIII, essa tecnologia passa a funcionar mais como um "sistema de diferenças" do que de similaridades: a anatomia feminina deixa de ser uma sombra suplementar do homem para ser lida exclusivamente em sua função de procriação ${ }^{12}$. Para Laqueur, foi somente nesse novo sistema que o homem e a mulher se tornam propriamente identidades sexuais - antes, afinal, havia apenas o homem e um receptáculo reprodutivo. É também no século XVIII que foram publicados dois tratados médicos clássicos que, para qualificarem a masturbação como patologia e vício moral, criaram a retórica do "abuso de si” e do risco de perda excessiva dos fluidos corporais. Não por acaso, supunha-se que tal risco seria mais agravante no corpo feminino, posto que a mulher já expele sangue regularmente em decorrência de sua natural "função de procriação".

Mas o real "perigo" da masturbação era, claro, o de subtrair os corpos da tecnologia heterossexual, de onde deriva a necessidade de produzir todo um conjunto de técnicas para disciplinar a mão masturbadora. De fato, como Foucault nos relata no curso $O$ poder psiquiátrico, houve uma proliferação de instrumentos de punição corporal no final do século XVIII: a camisa de força, as algemas, os colares com espinhos internos etc. Ao mencionálos, Foucault (2006, p. 130-133) ressalta as transformações, entre os séculos XVIII e XIX, não desses instrumentos, mas da função atribuída a eles. Antes do século XIX, eles exerciam funções de bloqueio, tortura e marcação de estigmas permanentes; depois, os mesmos instrumentos tornam-se ortopédicos, isto é, entendidos como meios de corrigir e adestrar o corpo. Mais precisamente, adquirem três características: são feitos para uso contínuo; precisam continuar

12 Donna Haraway, em sua análise crítica dos tratados de primatologia do século XIX (tributários a esse "sistema de diferenças" que emerge no século XVIII), assinalou como a masculinidade foi frequentemente descrita em função de sua aptidão em fabricar instrumentos e construir coisas, enquanto a feminilidade foi definida em função de sua disponibilidade sexual. Ver, a esse respeito, Haraway (1998, p. 9). 
surtindo efeito quando retirados; são homeostáticos, ou seja, quanto mais se resiste a eles, mais fazem efeito.

A passagem para o século XIX, como insistia Foucault, inaugurou um ambiente propício ao disciplinamento populacional: paralelamente à gestão política da sífilis (transformada em signo de prostituição), as diferenças sexuais já estavam cientificamente normatizadas, a ponto de se atribuir traços anatômicos e psicológicos, por exemplo, à homossexualidade, ao sadismo, à sodomia e à pedofilia. O fundamental era tornar visível a diferença entre normalidade e perversão - mesmo porque a burguesia europeia, reciclando um velho hábito aristocrático, buscava a todo custo prevenir-se do contágio sexual e, em especial, da contaminação colonial ${ }^{13}$. Se antes as práticas sexuais não reprodutivas (do onanismo aos sexos oral e anal) eram apenas reprovadas, a partir de então elas são registradas, estudadas, perseguidas e pretensamente “curadas”. Afinal, é nesse contexto que emerge a figura que Foucault denominou de “o indivíduo a corrigir”, que se estende da criança masturbadora ao monstro sexual ${ }^{14}$.

No âmbito da visualidade, a imagem do onanismo passou, ao longo do século XIX, do estereótipo da jovem mulher que deveria ser protegida de sua obsessão tátil para o do perverso masturbador homossexual, cujo desinteresse pela procriação ameaçava o futuro da espécie. (ROSARIO, 1997) Já na esfera do design, a fabricação dos aparelhos antionanistas (existentes desde o século XVI) ${ }^{15}$ assume uma dimensão inusitada nos Estados Unidos, onde indústrias como a Graham's Flour (de farinha) e a Kellogg's Corn Flakes (de cereais) lideravam a “produção de diversos instrumentos tecnológicos dedicados a regular as práticas domésticas, uma produção da vida comum que vai do café da manhã aos regimes do tato sexual, do Kellogg’s Corn Flakes aos cintos antimasturbatórios” (PRECIADO, 2017, p. 104-105), sendo estes majoritariamente masculinos. Considerando que tais aparelhos logo incorporaram um sistema de eletrodos para evitar a ereção espontânea, Preciado os relaciona às técnicas de indução do orgasmo feminino por estimulação elétrica:

Se por um lado a masturbação foi condenada pela Igreja a partir do Renascimento, para depois ser patologizada pela medicina no século XVII e, em seguida, tecnicamente reprimida durante o século XIX e XX mediante o uso de aparelhos mecânicos (e mais tarde elétricos), a histeria, paralelamente, será construída como uma 'doença feminina' e um conjunto igualmente numeroso de aparelhos será posto em funcionamento para permitir a produção técnica da chamada ‘crise histérica’. (PRECIADO, 2017, p. 110)

13 Ver, a esse respeito: Hardt e Negri (2001, p. 151-153).

14 Ver, a esse respeito, a aula de 22 de janeiro de 1975: Foucault (2001, p. 43-58).

15 Ao menos em termos formais, tais aparelhos são muito próximos aos cintos de castidade (em sua forma de armadura ou blindagem), embora sua função tenha se transformado a partir do século XVIII: o que antes servia para evitar a relação heterossexual passa a impedir o contato da mão com as genitais. 
Nesse registro, Preciado localiza num tratado clínico de Pierre Briquet, publicado em 1859, a ideia germinal do vibrador a partir do chamado tratamento de "titilação do clitóris", que tinha a desvantagem de demandar sessões muito longas e exaustivas - até os anos 1880, quando o vibrador foi propriamente inventado ${ }^{16}$. Novamente os Estados Unidos estavam na vanguarda tecnológica em virtude do advento, em 1888, do primeiro vibrador manual de uso doméstico. $\mathrm{O}$ aparato não fazia alusão alguma ao formato fálico e se tornou popular graças a um convidativo pôster que trazia a imagem de uma ninfa, no estilo clássico de Botticelli, voando no céu noturno por ocasião do vibrador que ela porta e que a eleva. Seu slogan era: "Boas notícias para todos os homens e mulheres. A maior descoberta médica já conhecida. Dr. John Butler’s Electro-Massage Machine (ou manipulador elétrico) para curar doenças em casa”"17.

Não podemos perder de vista que o orgasmo assim obtido continuava a ser visto como resultado de uma “crise histérica” (a própria noção de “orgasmo” sempre denotou uma convulsão abjeta) e que o diagnóstico da histeria indicava, até meados do século XX, um misto de melancolia, neurastenia, frigidez e tendência ao lesbianismo - ou seja, traços de "anomalia" (hetero)sexual. Não havia qualquer lugar, portanto, reservado ao prazer feminino nas teorias biológicas de reprodução da espécie. Com efeito, se os vibradores rapidamente passaram da cadeira clínica para a cama matrimonial, foi justamente para redobrar a submissão das mulheres, sujeitando-as simultaneamente ao diagnóstico de uma doença pressuposta e às “necessidades” de seus maridos.

Segundo Preciado, no entanto, foi também nessa confluência entre o trabalho médico e a pressão matrimonial que, como em “uma espécie de faca de dois gumes” (PRECIADO, 2017, p. 113), as mulheres puderam descobrir o prazer sexual. O que aí se “descobre”, não obstante, não é nenhum impulso natural, e sim a reação mecânica produzida por um sistema elétrico com precisão científica. Essa redução do prazer a um procedimento técnico instaurou um desvio imprevisto na tecnologia heteronormativa: a produção eficaz do prazer sexual fora da relação heterossexual. É por isso que, como Preciado insiste assertivamente, tanto o dildo quanto o vibrador nunca funcionaram como substitutos do pênis, mas como próteses da mão masturbadora. De fato, o pênis jamais foi capaz de vibrar, tampouco de manter-se à disposição por tempo indeterminado; por sua vez, a masturbação foi eletricamente potencializada justamente pela tecnologia que visava reprimi-la. Mesmo a chamada 'cinta peniana', apesar do nome e da aparência, também se afasta do pênis por funcionar, a um só tempo, como "mão

16 Os primeiros aparelhos, cabe destacar, eram usados exclusivamente por médicos, tinham o porte de cadeiras vibratórias e contavam com um sistema eletromecânico centrífugo, o chamado trunk-shaking, que produzia massagens rítmicas tanto no clitóris quanto nos outros músculos da região pélvica.

17 No original: “Glad tidings for all men \& women. The greatest medical discovery ever known. Dr. John Butler’s Electro-Massage Machine (or electric manipulator) for curing disease at home”. (MAINES, 2001, p. 14) 
enxertada no tronco e extensão plástica do clitóris”. (PRECIADO, 2017, p. 121) É nessa lógica que, de modo geral, uma série de artifícios inicialmente projetados para fins de repressão médica, doméstica, religiosa etc. será apropriada e ressignificada, desde o início do século XX, pelas subculturas gay, lésbica e sadomasoquista.

Ao insistir nesse tipo de inflexão tecnopolítica, Preciado quer evidenciar não apenas que as técnicas e os instrumentos não determinam nem são determinados por seus usos e funções, mas sobretudo que, pari passu, as identidades de sexo/gênero não são inerentes aos corpos. Tais identidades funcionam como próteses na medida em que são sempre incorporadas e, por conseguinte, podem ser desmontadas, remanejadas e reconstruídas: “A prótese pertence por um tempo ao corpo vivo, mas resiste a uma incorporação definitiva. É separável, desenganchável, descartável, substituível”. (PRECIADO, 2017, p. 163) Tal sorte de manobra - ou, mais precisamente, “design” -, por mais que possa efetivamente atravancar a máquina heteronormativa, não emerge fora dessa máquina ou de maneira completamente estranha a ela, e sim como uma espécie de efeito colateral que traz consigo usos e resultados imprevistos em torno daquilo que permanece uma mesma técnica, um mesmo corpo, uma mesma materialidade ${ }^{18}$.

Se, como vimos, a invenção e a manutenção da heterossexualidade sempre dependeram da negação das diversas formas de "perversão” sexual, as tecnologias heteronormativas carregam desde o início o germe das sexualidades alternativas, a exemplo das "perversões" que protagonizam o universo pornográfico. Contudo, não é somente nesse lucrativo e inesgotável complexo industrial (universalmente visível e acessível, mas sobre o qual não se pode falar) que residem os curtos-circuitos em potencial. Se olharmos com atenção, veremos a artificialidade e o lado estranho da heterossexualidade em toda parte onde ela se faz presente, desde os contos de fada infantis, passando pelo matrimônio, pelas instituições religiosas, até chegar no discurso médico $^{19}$. Significa, em suma, que o sexo foi inventado, desenhado e materializado ao mesmo tempo como prática, como categoria biológica e, sobretudo, como motor próprio de uma sociedade heterocentrada. Por conseguinte, a heterossexualidade talvez seja o design mais bemsucedido da história, dada sua persistência ao longo do tempo; desde o século passado, no entanto, ela tem se revelado um modelo frágil e oneroso para a (re)construção de corpos e sexualidades.

18 Isso se revela na medida em que, por exemplo, os "cintos antimasturbatórios desenhados para evitar o acesso da mão às genitais surpreendem por sua semelhança com as cintas penianas contemporâneas”. (PRECIADO, 2017, p. 109)

19 Conforme demonstra Preciado em sua análise detalhada das controvérsias implicadas nos procedimentos médicos para se verificar se um bebê é macho ou fêmea. Ver, a esse respeito, Preciado (2017, p. 123-144). 


\section{0 design prostético-sexual}

Essa maquinaria sexo-prostética é relativamente recente e, de fato, contemporânea da invenção da máquina capitalista e da produção industrial do objeto. (PRECIADO, 2017, p. 30)

O período em que desponta a fabricação de vibradores, no início do século XX, precede em poucas décadas o momento quando a medicina começa a desenvolver numerosas próteses em decorrência da Primeira Guerra Mundial. Com isso, e como que a contragosto, a noção de “masculinidade” se tornará (ou se revelará) progressivamente prostética. As primeiras próteses masculinas, diferentemente do vibrador, não tinham fins terapêuticos. Elas foram projetadas precisamente para transformar um ex-combatente amputado em um trabalhador industrial. Jules Amar, pioneiro do campo da ergonomia, publicou em 1916 o tratado La Prothèse et le travail des mutiles (A prótese e o trabalho dos mutilados), que apresenta o design inovador das chamadas "próteses funcionais", cuja falta de semelhança com a anatomia humana se justificava pela otimização da interação homem-máquina. Essas próteses, ademais, não contemplavam órgãos sexuais e se focavam em pernas-pedaladoras, braços-alavancas e mãos-pinças. Ora, não incluir nessa reabilitação “funcional” os soldados que perderam o pênis implica considerá-los, ainda que noutra dimensão do trabalho, "disfuncionais".

Detenhamo-nos no fato de que, embora hoje prevaleçam as chamadas "próteses plásticas" (de finalidade estética), sobretudo aquelas associadas à feminilidade (como os seios de silicone), historicamente foi o corpo masculino o primeiro a ter sido reconstruído prosteticamente. Já na Segunda Guerra Mundial, como se sabe, as mulheres estadunidenses foram incumbidas de trabalhar nas fábricas, além de continuar cuidando dos filhos e das "tarefas do lar". O bom desempenho dessas trabalhadoras revelou não só que elas sempre tiveram a mesma capacidade "braçal” dos homens, como também que era possível viver relativamente bem sem eles. Assim se iniciou uma guinada irreversível: quando os soldados retornaram aos lares, era como se ninguém mais estivesse os esperando. Suas esposas já estavam "munidas” com a mesma comida enlatada que os alimentava na guerra e os divórcios cresciam no mesmo passo em que afloravam as comunidades gays, de São Francisco a Nova York, preparando terreno para a revolução da pílula contraceptiva.

É preciso lembrar que, nesse contexto, a tecnologia bélica foi transformada em tecnologia de consumo com a mesma velocidade que a TV passou a transmitir imagens coloridas. Não surpreende, por exemplo, que os designers Charles e Ray Eames tenham obtido notoriedade a partir dos anos 1950: após terem produzido as macas do exército estadunidense, eles projetaram um amplo leque de mobiliário doméstico por meio da mesma técnica que eles aplicaram durante 
a guerra (moldagem de madeira acoplada a peças de aço pré-fabricadas). De forma análoga, a fabricação a baixo custo do plástico moldado, processo que já abrangia praticamente todos os objetos de consumo, serviu-se do ritmo acelerado de produção que outrora as indústrias empregavam nas metralhadoras e nos mísseis. E se o plástico também pôde se infiltrar na carne das(os) transexuais, é porque ele já estava “encarnado”, como ironiza Preciado, na esfera do entretenimento: “os novos protótipos hollywoodianos de masculinidade e feminilidade já eram tão artificiais que ninguém teria sido capaz de apostar um dólar para demonstrar que Elvis não era um drag king ou Marilyn uma transexual siliconada”. (PRECIADO, 2017, p. 203) ${ }^{20}$

Com efeito, desde quando Jules Amar explicitou, com seus operários prostéticos, que a masculinidade é tecnologicamente construída, a máquina capitalista teve que se ajustar para pôr a plasticidade dos corpos a serviço de uma nova forma de consumo - o que coincide, por exemplo, com a fundação da revista Playboy em 1953, cujo conteúdo não se reduzia a entretenimento erótico, antes pois abarcava uma nova pedagogia orientada ao homem solteiro (ainda que seu público tenha sido sempre composto majoritariamente por homens casados). Em sua tese de doutorado acerca da Mansão Playboy, Preciado (2014) mostra como o hedonismo extremo de Hugh Hefner (fundador e editor-chefe da revista durante quatro décadas) era indissociável de um regime “farmacopornográfico” regado a pílulas contraceptivas (para as Playmates que habitavam a mansão) e anfetamina (dentre outras drogas nas quais Hefner era densamente viciado).

É nesse mesmo período que, por outro lado, Preciado localiza a emergência da "lésbica butch”, isto é, a mulher homossexual assimilada, a princípio, como posição ativo-masculina em contraste com a chamada "lésbica femme" - embora, como salienta o autor, essa dicotomia heteronormativa se diluirá progressivamente sob a forma de práticas queer. A butch nasce, segundo Preciado, diretamente do ambiente industrial em que, durante a guerra, as mulheres descobriram não apenas uma habilidade inesperada de se acoplar com a máquina, como também o fato de os modos de produção não estarem naturalmente vinculados aos homens. A partir de então, “como uma espiã indiscreta, [a butch] irrompe na fria sala na qual o casal heterossexual assiste televisão e cria seus filhos”, e sai em busca não só da femme, como também de novos órgãos prostéticos: "primeiro o dildo, depois os hormônios, a própria carne”. (PRECIADO, 2017, p. 206)

Apesar das aparências, a butch nunca foi algo como uma masculinidade alternativa. Pois, como relata Preciado, é sempre a femme quem carrega o dildo na bolsa, de modo que "a butch

20 O termo “drag king” designa a prática feminina equivalente à “drag queen” (prática masculina de performar e se travestir como mulher). 
come a femme com o dildo que esta lhe deu” (PRECIADO, 2017, p. 208) - e se, como vimos, o dildo é uma prótese da mão masturbadora, e não do pênis, a mão experiente da butch serve de força motriz a uma prótese momentaneamente partilhada. Assim, a butch descobriu que é possível obter e fornecer prazer sexual sem precisar ter a posse de um órgão sexual. Não demoraria muito para descobrir, por conseguinte, que todos os gêneros são prostéticos, na medida em que podem ser casualmente incorporados. E, por mais que essa dinâmica possa parecer pós-humana e pós-evolutiva, a butch logo soube que ela não é nenhuma “exceção” da natureza; está apenas consciente do caráter ciborgue de todo corpo e identidade: o macho halterofilista não é menos prostético que uma travesti, que por sua vez não é menos artificial do que o corpo santo de uma freira.

Dito de outro modo, a butch talvez tenha sido a primeira a praticar deliberadamente um design prostético de corpos e sexualidades. Mas, conscientemente ou não, todos nós também o praticamos, em variados níveis, quando ingerimos um antibiótico, cortamos o cabelo, fazemos um transplante de medula óssea ou uma mera tatuagem. Isso implica "liberdade” na mesma medida em que nos sujeita, precisamente, a um regime biopolítico de produção e regulação dos modos de vida. Em todo caso, parece-me que tanto Foucault quanto Preciado preocupam-se mais em pensar as fissuras, as brechas da ordem, o ponto em que as coisas começam a deixar de ser ou parecer aquilo que supostamente sempre foram, o que culmina em certo princípio de design: não existe natureza por trás das coisas, das técnicas e das práticas. O humano é fruto do fazer humano.

O design se dá por meio de normas e identidades que atribuem autoridade a certos discursos e modos de viver. Mas toda normalidade é definida pelas margens: os corpos desajustados, os não-adaptados, os desviantes e os invisíveis. O design que os marginaliza é o mesmo que, geralmente sem o saber, viabiliza o gesto marginal. Foi nesse sentido que, nos anos 1980, Robert Venturi afirmou que a arquitetura devia aprender com Las Vegas, e que, nos anos 2000, Preciado postulou que a filosofia devia aprender com o dildo. Hoje, já está mais do que na hora de, no design, aprendermos com as próteses.

\section{Breve glossário contrassexual}

Longe de querer, aqui, contemplar todo o léxico conceitual que Paul Preciado emprega e propõe em sua filosofia, julgo pertinente definir alguns termos-chave não apenas no sentido de demarcar a rica especificidade de seu pensamento, mas antes para dar conta de conceitos aos quais não dei suficiente atenção - inversamente, não estão listados termos como "tecnologia” e “design prostético” por terem sido objetos dos tópicos abordados até aqui. Acredito que este 
breve glossário, portanto, vem a esclarecer possíveis dúvidas e questionamentos suscitados neste artigo.

Sexo: “O sexo, como órgão e prática, não é nem um lugar biológico preciso nem uma pulsão natural. O sexo é uma tecnologia de dominação heterossocial que reduz o corpo a zonas erógenas em função de uma distribuição assimétrica de poder entre os gêneros. [...] O processo de criação da diferença sexual é uma operação tecnológica de redução que consiste em extrair determinadas partes da totalidade do corpo e isolá-las para fazer delas significantes sexuais. Os homens e as mulheres são construções metonímicas do sistema heterossexual de produção e de reprodução que autoriza a sujeição das mulheres como força de trabalho sexual e como meio de reprodução”. (PRECIADO, 2017, p. 25-26).

Desejo/prazer sexual: Conjunto arbitrário de regulações inscritas nos corpos que asseguram a exploração material de um sexo sobre o outro. (WITTIG, 1992, p. 2-8) No século XIX, “com a ajuda de instrumentos mecânicos, realizaram-se intervenções no domínio do prazer feminino; enquanto, por um lado, se proibiu e se controlou a masturbação, por outro, o orgasmo feminino foi medicalizado e entendido como crise de histeria. O orgasmo masculino foi mecanizado e domesticado por meio de uma incipiente codificação pornográfica... A maquinaria estava pronta”. (PRECIADO, 2018, p. 77)

Órgãos sexuais: “Os órgãos sexuais não existem em si. Os órgãos que reconhecemos como naturalmente sexuais já são o produto de uma tecnologia sofisticada que prescreve o contexto em que os órgãos adquirem sua significação (relações sexuais) e de que se utilizam com propriedade, de acordo com sua 'natureza' (relações heterossexuais)”. (PRECIADO, 2017, p. 31) Em 1980, Monique Wittig (1992, p. 21-34) adotou o termo straight mind para qualificar a heterossexualidade não como uma orientação sexual, mas como um regime político que normaliza a prática sexual a partir da designação de certas partes do corpo (em detrimento de outras) enquanto órgãos reprodutivos. Em contrapartida, partes como a mão, a boca e o ânus ${ }^{21}$, por serem excluídos da função reprodutiva, não contribuem com a divisão dos sexos e, quando emulados por meio de próteses, podem induzir um curto-circuito na sexualidade normativa.

Corpo: Texto socialmente escrito pelos modos de (re)produção de uma sexualidade normativa. “A (hetero)sexualidade, longe de surgir espontaneamente de cada corpo recémnascido, deve se reinscrever ou se reinstruir através de operações constantes de repetição e de

21 Quanto ao ânus, Preciado assim o qualifica: “Um: o ânus é o centro erógeno universal situado além dos limites anatômicos impostos pela diferença sexual, onde os papéis e os registros aparecem como universalmente reversíveis (quem não tem um ânus?). Dois: o ânus é uma zona primordial de passividade, um centro produtor de excitação e de prazer que não figura na lista de pontos prescritos como orgásticos. Três: o ânus constitui um espaço de trabalho tecnológico; é uma fábrica de reelaboração do corpo contrassexual pós-humano. O trabalho do ânus não é destinado à reprodução nem está baseado numa relação romântica. [...] Pelo ânus, o sistema tradicional da representação sexo/gênero vai à merda”. (PRECIADO, 2017, p. 32) 
recitação dos códigos (masculino e feminino) socialmente investidos como naturais”. (PRECIADO, 2017, p. 26) Esse ritual de repetição e reiteração de um corpo sexuado é tanto o lugar da formação compulsória do sujeito heterossexual quanto, paradoxalmente, o espaço no qual acontece toda subversão possível. (BUTLER, 2003, p. 185-203)

Prótese: “A prótese não é essência. É trânsito. É efeito múltiplo e não origem única. Não existe mais do que em um contexto concreto: o do enxerto. Os instrumentos e as ferramentas, separados das práticas de poder ligadas à masculinidade, constituem o objeto de uma descontextualização contrassexual”. (PRECIADO, 2017, p. 207) Por conseguinte, “a butch dos anos cinquenta já é queer porque reconhece sua condição prostética, enquanto o macho ainda continua persuadido de sua superioridade natural”. (PRECIADO, 2017, p. 208)

Identidade sexual: “A identidade sexual não é a expressão instintiva da verdade prédiscursiva da carne, e sim um efeito de reinscrição das práticas de gênero no corpo. O problema do chamado feminismo construtivista é ter feito do corpo-sexo uma matéria disforme à qual o gênero viria a dar forma e significado dependendo da cultura ou do momento histórico". (PRECIADO, 2017, p. 29) Quanto ao sujeito sexual, Preciado o concebe não como ente autônomo de ação e conhecimento, mas como uma posição instável e localizada, em constantes renegociações estratégicas de identidade. O filósofo também nos alerta contra o hábito feminista de renaturalizar certas identidades femininas; nesse sentido, é preciso não perder de vista que, nos termos de Donna Haraway (1988, p. 590), “o único modo de encontrar uma visão mais ampla é estando em algum lugar em particular”.

Gênero: “O gênero não é simplesmente performativo (isto é, um efeito das práticas culturais linguístico-discursivas) como desejaria Judith Butler. O gênero é, antes de tudo, prostético, ou seja, não se dá senão na materialidade dos corpos. É puramente construído e ao mesmo tempo inteiramente orgânico. Foge das falsas dicotomias metafísicas entre o corpo e a alma, a forma e a matéria. O gênero se parece com o dildo. Ambos, afinal, vão além da imitação. Sua plasticidade carnal desestabiliza a distinção entre o imitado e o imitador, entre a verdade e a representação da verdade, entre a referência e o referente, entre a natureza e o artifício, entre os órgãos sexuais e as práticas do sexo. O gênero poderia resultar em uma tecnologia sofisticada que fabrica corpos sexuais”. (PRECIADO, 2017, p. 29)

Queer práxis: "David Halperin, seguindo as intuições de Foucault, denominou queer práxis esta forma de transformação de certas técnicas de dominação em técnicas de si, que hoje não duvidaríamos em denominar técnicas de construção de identidade”. (PRECIADO, 2017, p. 107-108) $)^{22}$ Preciado ilustra o conceito com numerosos exemplos, como o uso da tecnologia 
veterinária em práticas sexuais alternativas que interrompem e desvirtuam os circuitos de produção e distribuição do "prazer heteronormal”. Por isso, para Preciado, a dimensão tecnológica é tão inescapável quanto decisiva para a prática queer: o dildo e os demais instrumentos prostéticos, que simultaneamente compõem e resultam de um jogo complexo entre corpo e objeto (assinalando o caráter “ciborgue” da epistemologia queer), foram extraídos de tecnologias específicas de gênero (a produção heterossexual da feminilidade e da masculinidade) e passam a funcionar como avesso daquilo que tais técnicas e discursos (médicos, jurídicos, morais etc.) repreendiam e modelavam.

\section{Referências}

BECCARI, M. N. Discourse and place of speech in graphic/information design: Some philosophical considerations. Information Design Journal, Amsterdam, v. 24, n. 1, p. 67-79, 2018.

BUTLER, J. Problemas de gênero: feminismo e subversão de identidade. Rio de Janeiro: Civilização Brasileira, 2003.

DIDI-HUBERMAN, G. Invenção da histeria: Charcot e a iconografia fotográfica de Salpêtrière. Rio de Janeiro: Contraponto, 2015.

FOUCAULT, M. História da sexualidade I: a vontade de saber. São Paulo: Graal, 2005.

FOUCAULT, M. O poder psiquiátrico: curso dado no Collège de France (19731974). São Paulo: Martins Fontes, 2006.

FOUCAULT, M. Os anormais: curso no Collège de France (1974-1975). São Paulo: Martins Fontes, 2001.

HALPERIN, D. Saint Foucault: towards a gay hagiography. New York: Oxford University Press, 1995.

HARAWAY, D. "Manifesto ciborgue: ciência, tecnologia e feminismosocialista no final do século XX”. In: Tadeu, T. (org.). antropologia do ciborgue: as vertigens do pós-humano. Belo Horizonte: Autêntica, 2009. p. 33118.

HARAWAY, D. Primate visions: gender, race and nature. New York: Routledge, 1998.

HARAWAY, D. "Situated knowledges: the science question in feminism and the privilege of partial perspective". Feminist Studies, v. 14, n. 3, p. 575-599, 1988.

HARDT, M.; NEGRI, A. Império. Rio de Janeiro: Record, 2001.

KRAFFT-EBING, R. Psychopathia sexualis: the classic study of deviant sex. 
New York: Arcade, 1998.

LAQUEUR, T. Making sex: body and gender from the Greeks to Freud. Cambridge: Harvard University Press, 1992.

LAURETIS, T. “A tecnologia do gênero”. In: HOLLANDA, H. B. (org.). Tendências e impasses: o feminismo como crítica da cultura. Rio de Janeiro: Rocco, 1994a. p. 206-242.

LAURETIS, T. The practice of love: lesbian sexuality and perverse desire. Indianapolis: Indiana University Press, 1994b.

MAINES, R. P. The technology of orgasm: “hysteria”, vibrators and women’s sexual satisfaction. Baltimore: John Hopkins University Press, 2001.

PRECIADO, P. B. Manifesto contrassexual: práticas subversivas de identidade sexual. São Paulo: n-1, 2017.

PRECIADO, P. B. Pornotopia: an essay on Playboy's architecture and biopolitics. New York: Zone, 2014.

PRECIADO, P. B. Testo Junkie: Sexo, drogas e biopolítica na era farmacopronográfica. São Paulo: n-1 Edições, 2018.

ROSARIO, V. A. The erotic imagination: French histories of perversity. New York: Oxford University Press, 1997.

RUBIN, G. Políticas do sexo. São Paulo: Ubu, 2017.

WITTIG, M. The straight mind and other essays. Boston: Beacon, 1992. 